\title{
Self-Optimization Simulation Model of Short-Term Cascaded Hydroelectric System Dispatching Based on the Daily Load Curve
}

\author{
Xin-Ming Zhang • Li-ping Wang • Ji-wei Li • \\ Yan-ke Zhang
}

Received: 2 April 2013 / Accepted: 22 September 2013 /

Published online: 15 October 2013

(C) The Author(s) 2013. This article is published with open access at Springerlink.com

\begin{abstract}
Short-term optimization dispatching of cascaded hydroelectric system with day (or week) cycle is of great value in practical implementation, such as improving grid stability, more power benefits. This study proposes a short-term self-optimization simulation model for cascaded hydroelectric system dispatching, which balances the requirements both of the generation side and the demand side. Three conflicting objectives for the management of hydropower generation are incorporated in the cascaded hydroelectric system. And in this model, the reasonable physical factors are chosen to coordinate the contradiction. According to the characteristics of the self-optimization simulation technique, for example clear physical meaning, more perfect simulation, no dimension limitation, artificial adjustment with the accumulated experience and so on, a new solving idea for this model is set up. And the new operation model is illustrated in the middle reaches of the Chinese Jinsha River, where eight cascades are planned. Considering the different startup time and combinations, the results of the joint operation compared to the single reservoir operation has provided important demonstration for the investment entities, simultaneously the solving efficiency and quality of this model are good for implementing in practical.
\end{abstract}

Keywords Short-term dispatching $\cdot$ Self-optimization simulation $\cdot$ Multi-objective $\cdot$ Jinsha River

\section{Introduction}

Energy is a major strategic issue that concerns the overall human and social development. The historical data has attested to a strong relationship between the availability of energy and economic activity. According to recent IEA report (2007), with rapid economic development, the growing rate of global energy demand is about $1.6 \%$ per year, and the total quantity is

X.-M. Zhang $(\bowtie) \cdot$ L.-p. Wang $\cdot$ J.-w. Li $\cdot$ Y.-k. Zhang

Renewable Energy Institute, North China Electric Power University, Beijing, China

e-mail: jingfeng111284@sina.com

L.-p. Wang

e-mail: lipingw@163.com 
predicted to achieve about $700 * 10^{8}$ Joule/Year by 2030 (Pekala et al. 2010). However, at present, more than $80 \%$ production of worldwide primary energy has been coming from combustion of fossil fuels, which some day will inevitably lead to the problem of depletion. And it highlights how vulnerable the energy supply is to political conflict when two oil disruptions of the Middle East happened in the 1970s. Moreover, the problem of environmental pollution resulting from the use of fossil energy is becoming more and more serious. For example, greenhouse gas, acid rain, and particulate matter are all serious threat to human health. The renewable energy is the longterm potential actions for sustainable development, such as solar energy, wind energy, hydropower energy, biomass energy, and geothermal energy. And hydropower, as the most important sustainable energy source, has been a competitive technology for more than a century. It contributes one-fifth of the power generation of the world. In fact, for several OECD countries, more than $50 \%$ share of electricity generation is hydropower, and in some other countries, hydropower is the only domestic energy resource. In a word, comparing to other renewable energy, hydropower plays a more important role in electricity generation.

In China, the continuous increase of energy consumption has become more apparent because of the rapid industrialization, urbanization and modernization. The "Twelve 'Five Year' Electrical Plan in China", has made it clear that hydropower will be placed in the first priority amongst all types of the electricity generation. At present, $213.4 \mathrm{GW}$ of the Chinese energy, that is $22.2 \%$, is from hydropower plants. The hydropower installed capacity will reach $284 \mathrm{GW}$ and $330 \mathrm{GW}$ in 2015 and 2020, respectively. By then, the total hydropower installed capacity in China will be equivalent to the summation of the other top seven countries in the world (Based on data of 2007). The characters of the hydropower system affect the security and economic operation of Chinese power grid, since the features are so rare, complicated, and unique in the world history. In general, most constituents of the Chinese hydropower systems are cascade hydropower stations, and the operation and management of the cascaded hydropower stations is usually a multi-objective problem. So it is becoming more and more significant, urgent and difficult to determine the optimal hydro generation plan in China.

At present, low utilization efficiency and high waste are two outstanding characteristics of the Chinese developed hydropower operation. According to statistics, the electricity reduced per year is up to 20 billion $\mathrm{kWh}$ only because of head loss. So researches on the optimal scheduling of the cascaded hydroelectric system should be carried out, which can improve the economic benefits without any additional investment. Medium and long term hydroelectric optimal scheduling generally have certain significance in the planning and macro-guidance because of the random and versatile natural runoff. While short-term optimal scheduling of day (or week) cycle becomes more practical. And it plays an important part in improving grid stability and implementing the optimal benefit of the power generation. Many researchers have focused on the short-term cascaded optimal scheduling for a long time. And lots of optimal technologies have been studied to solve this problem, including dynamic programming (DP) (Zhang 2004), network flow (Oliveiraa and Soaresb 2005), mixed-integer quadratic programing (Catalao and Pousinho 2010), particle swarm optimization (PSO) (Ostadrahimi and Miguel 2012), and differential evolution (DE) (Yuan et al. 2010) etc. Generally, there are some defects of those methods, such as dimensionality difficulty, convergence instability, and algorithm complications. So these methods can't be always suitable for the complex cascaded hydroelectric system while the requirements become more and more.

Actually, all of the short-term scheduling technology can be divided into two categories: optimization and simulation. The optimization method is a kind of mathematical model with the objective functions and constraints. Its optimization process is good for seeking the excellent direction of the overall system. However, the inherent weakness, such as "dimension difficulty" and poor simulation degree can't be ignored. The simulation technology can be viewed as a kind 
of "impulse response" model. Some input information will produce a corresponding output following the interior predetermined logic judgment. So the external controllability is its dominating character. The advantages of this method are understandable, strong simulative, and adjustable to actual situation and professional experience. However, sometimes it is too entangled in details to grasp the overall goal. But in practical application, people hope the system doesn't only optimize along the overall decision direction, but also can proceed under control. Therefore the self-optimization simulation technology is produced through combining the characteristics of the two methods. O.T.sigvaldason (1976) succeeded in inserting an optimized sub-model into the simulation model, and under controlling the penalty coefficient, simulated different operating strategies of the optimal running. The work was proved to be significant. Lei (1989), with the basic principles of modern control theory, added the links of identification, optimal control and guidance into the simulation process, and then in the east route of South-to-North Water Transfer Project planning, proposed the corresponding self-optimization simulation model and achieved satisfactory results. Li (2000) built the Yellow River upstream cascade water real-time scheduling optimization model using the self-optimization simulation technology, and the results demonstrated that the model was simple and flexible in practice. Afzali et al. (2008) presented a multireservoir reliability-based simulation model for the integrated operation of the reservoir system. The models were applied to a hydropower system in Iran as a case-study. Khan and Babel (2012) applied the Reservoir Optimization-Simulation with Sediment Evacuation (ROSSE) model with the aim of minimizing irrigation shortages in the Tarbela Reservoir, Pakistan, and also calculated the suitable values of various GA parameters required to run the model through a sensitivity analysis. Yu (2012), from the point of view that the power output characteristics should be as consistent as the system load characteristics, built models respectively according to two scheduling modes, one of which is the day scheduling mode with the maximum daily generation capacity as its optimization criterion, the other is the concentrated peaking load mode with the maximum peaking capacity as the optimization criterion.

According to the above analysis, the short-term scheduling is of great importance in practice and theory because of its obvious intermediate link position for connecting the mid-long term scheduling and economical operation. This paper aims to develop a practical model for the shortterm optimization scheduling of Chinese cascaded hydroelectric system, through coupling the self-optimization simulation technology with the multi-objective ideology. From the point view of the power supply and power demand, it should not only consider the total generating capacity to obtain the whole benefit, but also need to ensure the output process as consistent as the load curve for keeping the power grid safe. Meanwhile the peak generating capacity should be taken into account. So this model is a typical multi-objective decision problem with three objective functions regarded. And the results obtained from the Jinsha River can help generate the desired decision that the short-term self-optimization simulation scheduling model of Chinese cascaded hydroelectric system will be able to not only satisfy the requirements of the power demand parts but also meet the requirements of the supply parts as far as possible.

\section{Self-Optimization Simulation Model of Short-Term Cascaded Hydroelectric System Scheduling Based on the Daily Load Curve}

\subsection{Self-Optimization Simulation Principle}

General simulation is a response progress that the simulated output wholly depends on the input elements. The process is revealed in part (1) Fig. 1 (dashed line range). But in this way the output is only a natural response because of the immutable and uncontrollable input 


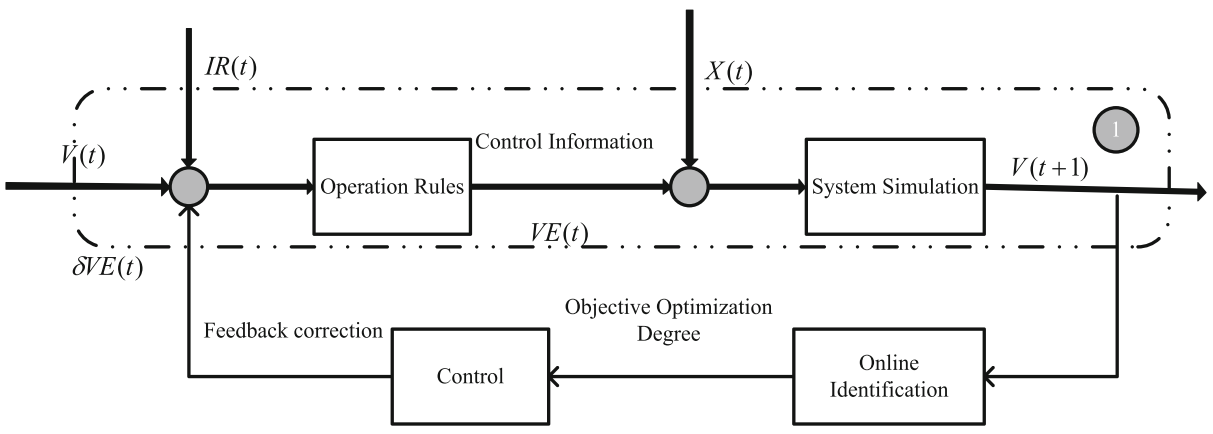

Fig. 1 System simulating and controlling progress

sequence. The only way for obtaining the optimal target is to establish the searching response surface. However, the response surface will be becoming more and more complex with the increasing control system states. Even if at last the optimal result is achieved by this simulation, but it inevitably has wasted a long time for the calculation.

Therefore, it is necessary to seek a controllable simulation structure to change the open-loop control mode to closed-loop (negative feedback) control. When output is retroacted to the input terminal, a simulating control line will be formed automatically with the relative feedback to guide the continuous running. The simulating process won't stop circulating until the simulated results tend to the optimal target. In the reservoir system, since the optimal result controlled is not known, so it is necessary to generate a self-adaptive link with automatic identification, judgment and amendment. A control correction will be generated to guide the simulation system further optimal, when the optimal performance of the simulation control line is identified by the output online. The correction together with system operating rules and other constraints guides the system to proceed more reasonably. As a result, the simulation control line gradually converges to the optimal control line, and simultaneously the simulated results tend to the optimal results as far as possible.

\subsection{Self-Optimization Simulation Model}

\subsubsection{Objective Function}

The optimization criteria of the cascaded hydroelectric system should fully meet the requirements of the grid scheduling departments, especially the characteristics of the load curve. Namely the actual output process should be as consistent as the system load instruction process. And it is well known to all that the more peak load taken on, the more positive affection is for the grid system and the generate electricity supplier. Therefore, the maximum peaking power is another optimization criterion. At last it is the maximum generating capacity target through coordinating running program of the flat and valley period. From the above analysis, it's the objective functions are respectively arranged as: the minimum total deviation between the actual power generation process and system load instruction process during scheduling period; maximum cascaded total peaking capacity; maximum cascade total power generation. The formulas are as follows:

$$
T D=\min \left\{\sum_{n=1}^{N} \sum_{t=1}^{T}\left(\left(N_{n, t}-F N_{n, t}\right)^{2}\right)\right\}
$$




$$
\begin{gathered}
T P E=\max \sum_{n=1}^{N} \sum_{t=1}^{T_{P}} N_{p n, t} \bullet \Delta t \\
T E=\max \sum_{n=1}^{N} \sum_{t=1}^{T} N_{n, t} \bullet \Delta t / 3600=\sum_{n=1}^{N} \sum_{t=1}^{T} k q_{n, t} H_{n, t} \bullet \Delta t / 3600
\end{gathered}
$$

Where, $T D$ is defined as the total deviation between the power generation process and the system desired process during scheduling period; TPE is the total peaking generating capacity of all the peak load period; $T E$ is the total generating capacity of the scheduling period; $N_{n, t}$ is the actual output of hydropower $n$ in period $t ; F N_{n, t}$ is the power load curve's indicating output of hydropower $n$ in period $t ; N_{p n, t}$ is the actual peak-load output of hydropower $n$ in period $t ; q_{n, t}$ is the generation flow in period $t$, whose unit is $\mathrm{m}^{3} / \mathrm{s} ; H_{n, t}$ is the average power head of hydropower $n$ in period $t$, whose unit is $m ; \Delta t$ is the length of time period, whose unit is $s ; k$ is the output coefficient; $T$ is the total number of time periods; $N$ is the total number of cascade hydropower stations.

Note: abnormal extra disposable water is the abandoned water while the reservoir level is below the normal water level (or flood control level) or the power plants' output has not reached the expected output.

\subsubsection{Constraint Conditions}

(1) Reservoir water balance constraints:

$$
\begin{gathered}
V_{n}(t+1)=V_{n}(t)+\left(Q_{n, R}(t)-Q_{n, C}(t)-Q_{n, L}(t)\right) \cdot \Delta T \\
Q_{n, R}(t)=I_{n, R}(t)+e^{\gamma} \cdot\left(s_{n-1, q}(t-\tau)+q_{n-1, f}(t-\tau)\right) \\
Q_{n, C}(t)=s_{n, q}(t)+q_{n, f}(t)
\end{gathered}
$$

Where, $V_{n}(t), V_{n}(t+1)$ represent the reservoir water volume respectively for the beginning and end time of period $t ; Q_{n, R}(t), Q_{n, C}(t), Q_{n, L}(t)$ stand for separately inflow, outflow, lost flow of hydropower $n$ in period $t$ (evapotranspiration, seepage water losses and so on); $s_{n-1, q}(t-\tau), q_{n-1, f}(t-\tau)$ are the disposable flow and the generation flow respectively that are from the reservoir $n-1$ to reservoir $n$ in the period $t-\tau, \tau$ is the time that the stream lasts from the reservoir $n-1$ to reservoir $n ; s_{n, q}(t), q_{n, f}(t)$ respectively represent the disposable flow and the generation flow of reservoir $n$ in period $t ; \Delta T$ is the length of calculating period; $e^{\gamma}$ is the flattening coefficient, for which $\gamma$ is a change parameter. In general, $e^{\gamma}$ and $\tau$ will take on different values with the different connections of the cascade hydropower stations group.

(2) Reservoir node water balance constraints:

$$
Q_{n+1, C}(t)=Q_{n, C}(t)+Q_{n, R}(t)-Q_{n, U}(t)-Q_{n, L}(t)+Q_{n, T}(t-\tau)
$$


Where, $Q_{n+1, C}(t)$ is the outflow of reservoir $n+1$ within period $t ; Q_{n, C}(t)$ is the outflow of reservoir $n$ within period $t ; Q_{n, R}(t)$ indicates the interval water flow between the reservoir $n$ and reservoir $n+1$ within period $t ; Q_{n, U}(t)$ represents the demanded water flow of hydropower $n$ within period $t ; Q_{n, L}(t)$ is interval water loss flow of reservoir $n$ within period $t ; Q_{n}$, ${ }_{T}(t-\tau)$ represents the withdrawal water flow of reservoir $n$ within period $t-\tau$, that is, the withdrawal water on agriculture, industry, life and so on of the above node, will be considered as the inflow runoff of next node storage considerations. It can select the corresponding coefficient method to determine the value according to the task of water supply and the different wet, normal, dry season.

(3) Reservoir storage capacity constraints (or water level constraints):

$$
V_{n, \min }(t) \leq V_{n}(t) \leq V_{n, \max }(t)
$$

Where: $V_{n, \min }(t)$ is the minimum volume allowed of hydropower $n$ in period $t$, and generally is the dead capacity; $V_{n, \max }(t)$ is the maximum volume allowed of hydropower $n$ in period $t$, and is generally the corresponding capacity of normal water level, but in flood season, is the corresponding capacity of the flood protection limited water level.

(4) Hydropower station machine flow constraints:

$$
Q_{m, M, \min }(t) \leq Q_{m, M}(t) \leq Q_{m, M, \max }(t)
$$

$Q_{m, M, \min }(t), Q_{m, M, \max }(t)$ represent the minimum and maximum machine flow of hydropower $m$ in period $t$, respectively.

(5) Hydropower station output constraints:

$$
N_{m, \min }(t) \leq N_{m}(t) \leq N_{m, \max }(t)
$$

$N_{m, M, \min }(t), N_{m, M, \max }(t)$ represent respectively the minimum and maximum allowable output of hydropower $m$ in period $t$.

(6) Hydropower station discharge flow constrains:

$$
Q_{m, C, \min }(t) \leq Q_{m, C}(t) \leq Q_{m, C, \max }(t)
$$

$Q_{m, C, \min }(t), Q_{m, C, \max }(t)$ represent the minimum and maximum outflow of hydropower $m$ in period $t$ respectively.

(7) Reservoir station boundary condition constraint:

$$
Z_{n}(t)=Z_{b} \quad Z_{n}(t+1)=Z_{e}
$$

$Z_{n}(t)$ is the reservoir level at the beginning of the scheduling period of Reservoir $n, Z_{n}\left(t^{+}\right.$ 1) is the reservoir level at the end of the scheduling period of Reservoir $n$.

(8) Variable nonnegative constraints. 


\section{The Solving Technique for Self-Optimization Simulation Model}

\subsection{Solving Ideas and the Block Diagram}

According to the theory of multi-objective decision making, this paper selects coordination factors with the actual physical background to convert the multi-objective problem to a single objective problem. Firstly it is to analyze the objective function of the minimum cascade hydropower stations' total deviation. When the power generation process in each scheduling calculation period is reconciled with the load curve generation, the $T D$ target value will be zero with condition that there is no abnormal extra disposable water, to the contrary, $T D$ will obviously be bigger than zero. Secondly, the objective function of the maximum peaking power is considered. In order to coordinate the two optimization criteria, a weighting factor $W_{n, t}$ with physical meaning is introduced. The transforming form is as follows:

$$
\min \left\{\sum_{n=1}^{N} \sum_{t=1}^{T} W_{n, t}\left(N_{n, t}-F N_{n, t}\right)^{2}\right\}
$$

From the point view of taking on larger peak and valley load, the $W_{n, t}$ selected is taken as the punishment factor of the unit output which actually maintains a certain ratio to $F N_{n, t}$. When $F N_{n, t}$ represents the output of peak load periods, $W_{n, t}$ is necessarily large according to its proportional relationship. Hence, under this condition the aim to meet the minimum $T D$ objective, only can be achieved by choosing the strategy that $\left(N_{n, t}-F N_{n, t}\right)$ is relatively smaller. And it works the other way as well. Finally it is to consider the objective function of cascade hydropower total generating capacity with taking the system specified load as a lower limit to fulfill.

$$
\max \left\{\begin{array}{l}
W_{1}\left[\sum_{n=1}^{N}\left(\sum_{t=1}^{m} C_{p n, t}\left(N_{p n, t}-F N_{n, t}\right)+\sum_{t=m+1}^{T} C_{l n, t}\left(F N_{n, t}-N_{l n, t}\right)\right)\right] \\
+W_{2}\left[\sum_{n=1}^{N}\left(\sum_{t=1}^{m} C_{P n, t}\left(N_{P n, t} \bullet \Delta t-F E_{n, t}\right)+\sum_{t=m+1}^{T} C_{L n, t}\left(N_{L n, t} \bullet \Delta t-F E_{n, t}\right)\right)\right]
\end{array}\right\}
$$

Where, $[1, m]$ is the peak load stage; $[m+1, T]$ is the valley stage; $W_{1}, W_{2}$ represent the weight for the hydropower peaking power and power generation respectively; $C_{p n, t}$ is the unit output reward (punishment) when the power generation is increased (decreased) in the peak period; $C_{l n, t}$ is the unit output reward (punishment) when the power generation is decreased (increased) in the valley period; $C_{p n, t}, C_{l n, t}$ are both larger than zero; $F E_{n, t}$ is the generated output for each period according to the system specifying output process line; $C_{P n, t}$ is the reward or supply price in peak period when hydropower station adds the unit output; $C_{L n, t}$ is the reward or supply price in valley period when hydropower station adds the unit output. In order to consider the three objectives, the coordination factors usually are chosen as the following:

$$
\begin{gathered}
C_{p n, t}=F N_{n, t} / \max \left\{F N_{n, i} \mid i \in[1, T]\right\} \text { or } C_{p n, t}=F N_{n, t} t \in[1, m] \\
C_{l n, t}=F N_{n, t} / \max \left\{F N_{n, i} \mid i \in[1, T]\right\} \text { or } C_{l n, t}=F N_{n, t} t \in[m+1, T]
\end{gathered}
$$




$$
\begin{gathered}
C_{P n, t}=F E_{n, t} / \sum_{i=1}^{T} F E_{n, i} \text { or } C_{P n, t}=F E_{n, t} t \in[1, m] \\
C_{L n, t}=F E_{n, t} / \sum_{i=1}^{T} F E_{n, i} \text { or } C_{L n, t}=F E_{n, t} t \in[m+1, T]
\end{gathered}
$$

Supposing: $W_{1}=W_{2}=1, C_{p n, t}+C_{P n, t}=F N_{n, t}, C_{l n, t}+C_{L n, t}=F N_{n, t}$, then the objective function can be simplified to the following form:

$$
\max \sum_{t=1}^{T} F N_{n, t}\left(\sum_{n=1}^{N}\left(N_{n, t}-F N_{n, t}\right)\right)
$$

The basic solving idea is indicated as follows. First step: considering the influence factors, such as reservoir inflow forecasted, water supply plan, water propagation, water loss and so on, the calculation method can be described as the direction is top to down (downstream direction) and the calculation period is from the end to the beginning (anticlockwise timing). The purpose is to deduce the minimum and maximum controlling water level line for each period and reservoir. Second step: the output value $N$, whose normalizing ratio is 1 , is assumed as the installed capacity. The other daily output values can be figured out based on the load curve ratio calculated and the installed capacity presumed. Therefore, the initial output line comes into being. Third step: according to the process line of initial output, the system starts simulating and running with downstream direction (the direction is top to down) and clockwise timing. Then it identifies the reservoir end state. If the water level of this period meets the appointed limits, the system moves on to the next period process. If not, the running process of this period will be simulated again with a feedback correction. The simulation time doesn't go to the next period until the identified water level of this period can fulfill the assumed requirements. At the end of the scheduling period, it's time to identify the final water level and the abnormal extra disposable water. The system starts simulating a new cycle with the output feedback correction formed till the end states of all reservoirs are satisfied the presumed requirements. Finally, it goes to identify the cascade total target. The specific steps are shown in the block diagram in Fig. 2.

\subsection{Solving Steps}

\subsubsection{The Controlling Equations of the Maximum and Minimum Reservoir Water Level}

According to the forecasting inflow and the requirements of the water supply in the control area, the controlling lines of the maximum and minimum water level for each period and reservoir is deduced through the calculation method whose direction is top to down (downstream direction) and calculation period is from the end to the beginning (anticlockwise timing). The calculation equations are as follows:

$$
V L L_{n}(t)=V L_{n}(t+1)-\sum_{i=k(n-1)+1}^{k(n)}\left[Q_{i, R}(t)-Q_{i, U}(t)+Q_{i, T}(t-\tau)-Q_{i, L}(t)\right] \cdot \Delta t+Q_{n, C, \min }(t) \cdot \Delta t
$$




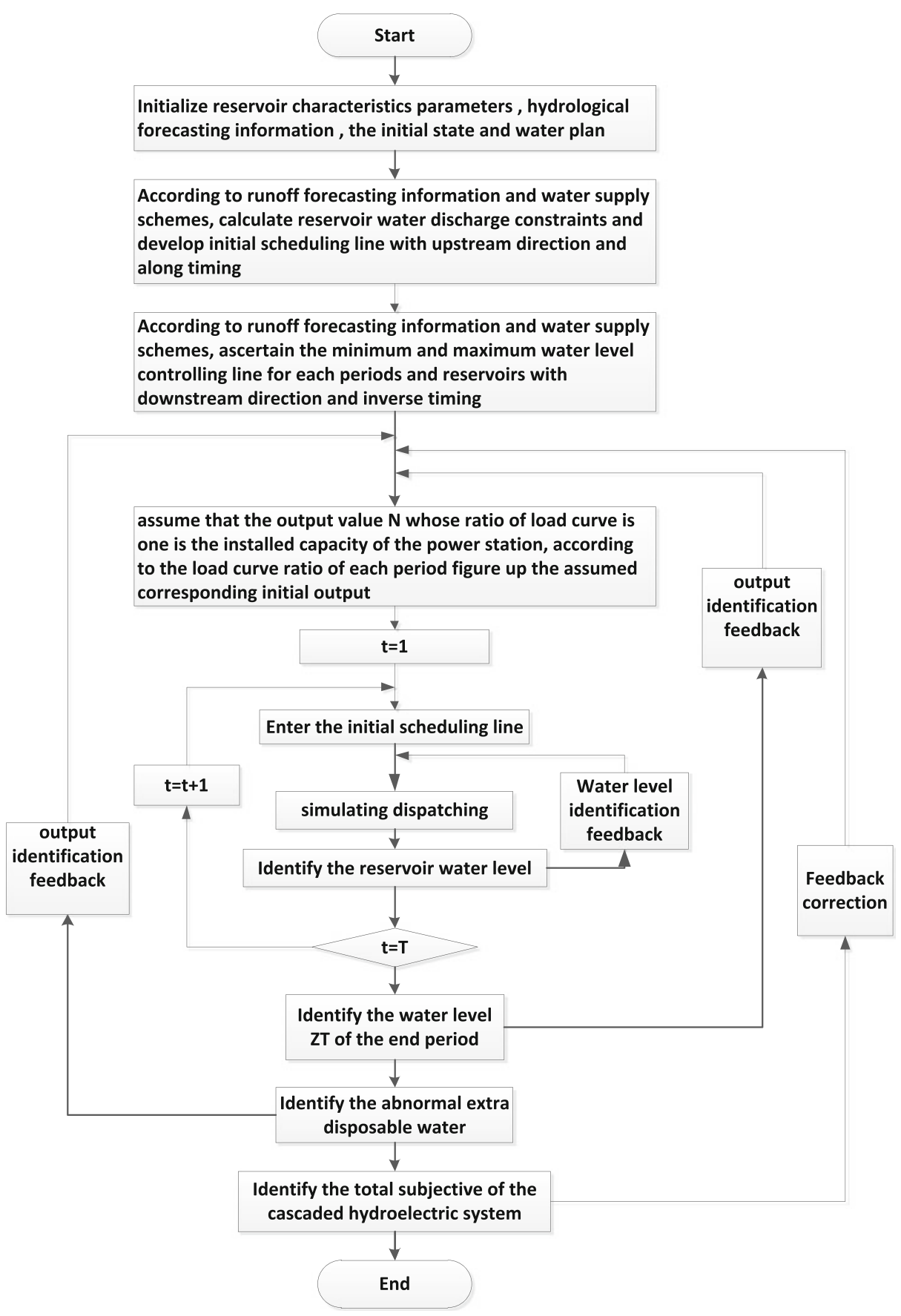

Fig. 2 Schematic of the self-simulation optimization model

$$
V L_{n}(t)=\min \left\{V L L_{n}(t), V_{n, \min }(t)\right\}
$$




$$
\begin{aligned}
V H L_{n}(t)= & V H_{n}(t+1)-\sum_{i=k(n-1)+1}^{k(n)}\left[Q_{i, R}(t)-Q_{i, U}(t)+Q_{i, T}(t-\tau)-Q_{i, L}(t)\right] \cdot \Delta t \\
& +Q_{n, C, \max }(t)^{\cdot \Delta t}
\end{aligned}
$$

$$
V H_{n}(t)=\min \left\{V H L_{n}(t), V_{n, \max }(t)\right\}
$$

Where: $V L_{n}(t)$ is the corresponding minimum capacity of the reservoir $n$ in period $t$; the $V H_{n}(t)$ is the corresponding maximum capacity of the reservoir $n$ in period $t ; Q_{n, R}(t), Q_{n, C}(t)$ can be gotten from the formulas (5) and (6), respectively; $k(n)$ represents the total rivers of the reservoir $n$ above.

\subsubsection{Reservoir Water Supply Constraints and Initial Scheduling Line Calculation Model}

In order to determine the lower constraints limits of the reservoir water supply, it adopts upstream direction and clockwise timing. At first it decides the running process clockwise timing on the condition of meeting its own water supply. Then it calculates the minimum complement water in accordance with the water shortage, together with the other minimum requirements. Through the downstream direction simulation, the new water replenishment requirements are coupled back when the node of lower reaches adjusts its runoff process. Water shortage computing model of the two adjacent reservoirs is as follows:

$$
\begin{gathered}
Q_{n, A}(t)=Q_{n, S}(t)+\Delta Q_{n}(t) \\
Q_{n, S}(t)=Q_{n, R}(t)-Q_{n, U}(t)-Q_{n, L}(t) \\
\Delta Q_{n+1}(t)= \begin{cases}0 & (n=0) ; \\
Q_{n, T}(t--\tau) & Q_{n, A}(t) \leq 0 ; \\
Q_{n, T}(t--\tau)+Q_{n, A}(t) & Q_{n, A}(t)>0 ;\end{cases} \\
Q_{n, T A}(t)=\sum_{i=k(n)+1}^{k(n)+j(n)} Q_{i, A}(t) \\
Q_{n, C, \min }(t)=\max \left\{Q_{n, T A}(t), Q_{n, M, \min }(t)\right\}
\end{gathered}
$$

Based on the drainage lower limit constraints, the initial schedule line determined is as follows:

$$
Q_{n, C, \text { begin }}(t)=\min \left\{Q_{n, C, \min }(t), Q_{n, C, \max }(t)\right\}
$$

Where: $Q_{n, R}(t), Q_{n, C}(t)$ as shown can be got from the formulas (5) and (6), respectively; $Q_{n, T A}(t)$ is the minimum replenishment water of reservoir $n$ in period $t ; Q_{n, C, \min }(t)$ is the discharge water low limit of reservoir $n$ in period $t ; Q_{n, C \text {,begin }}(t)$ represents the beginning scheduling value of reservoir $n$ in period $t ; k(n)$ represents the total rivers of the reservoir $n$ 
above; $j(n)$ is the total direct supply rivers of reservoir $n$; remaining symbols are the same meaning as above.

\subsubsection{The Calculating Method of the Reservoir Initial Output Curves}

In order to compare conveniently, the first step is to normalize the output values of the load curve given by the power grid. Then the output value $\mathrm{N}$ whose ratio is 1 is assumed as the installed capacity, namely the day maximum output. Finally, the other corresponding initial outputs are figured up according to the load curve ratio of each period.

\subsubsection{Reservoir Operation Simulation Model}

The system proceeds with the downstream direction and the clockwise timing period by period. The simulating equations of the calculation progress are as follows:

$$
\begin{gathered}
V_{n}(t+1)=V_{n}(t)+\left[\sum_{i=k(n-1)+1}^{k(n)}\left(Q_{i, R}(t)-Q_{i, U}(t)-Q_{i, L}(t)\right)-Q_{n, C}(t)\right] \cdot \Delta T \\
N_{n}(t)=\eta(n) \cdot Q_{n, M}(t) \cdot H_{n, \text { ave }}(t) \\
Q_{n, M}(t)=\min \left\{Q_{n, C}(t), Q_{n, M, \max }(t)\right\} \\
H_{n, \text { ave }}(t)=H_{n, \text { up }}(t)-H_{n, \text { down }}(t)-\Delta H_{n}(t)
\end{gathered}
$$

Where: $Q_{n, R}(t), Q_{n, C}(t)$ can be gotten from the formulas (5) and (6), respectively; $k(n)$ represents the total rivers of the reservoir $n$ above; $\eta(n)$ is the output coefficient of power station $n ; H_{n \text {,ave }}(t)$ is the average power head of power station $n ; H_{n, u p}(t), H_{n, \text { down }}(t)$ represent respectively the upstream and downstream average water level of reservoir $n$ in period $t$; $\Delta \mathrm{H}_{\mathrm{n}}(\mathrm{t})$ is the head loss of power station $n ; \mathrm{Q}_{\mathrm{n}, \mathrm{M}}(\mathrm{t})$ is the power flow of power station $n$ in period $t$.

\subsubsection{The Online Identification of the Feedback System}

According to the control theory and the principle of feedback correction, this paper applies the four layer identification feedback structures to solve the self-optimization simulation model established. In each layer a corresponding correction is coupled back through identifying the specified scalar. At last the satisfying solving scheme is generated step by step with iterating and looping. The feedback structure is as Fig. 3.

\section{Case Study}

The Jinsha River is the upper reaches of the Yangtze River. It starts from Yushu of Qinghai Province to Yibin of Sichuan Province. The whole length is $2291 \mathrm{~km}$, catchment area is $362000 \mathrm{~km}^{2}$, the river falls over $4000 \mathrm{~m}$, and the multi-annual average discharge is about 


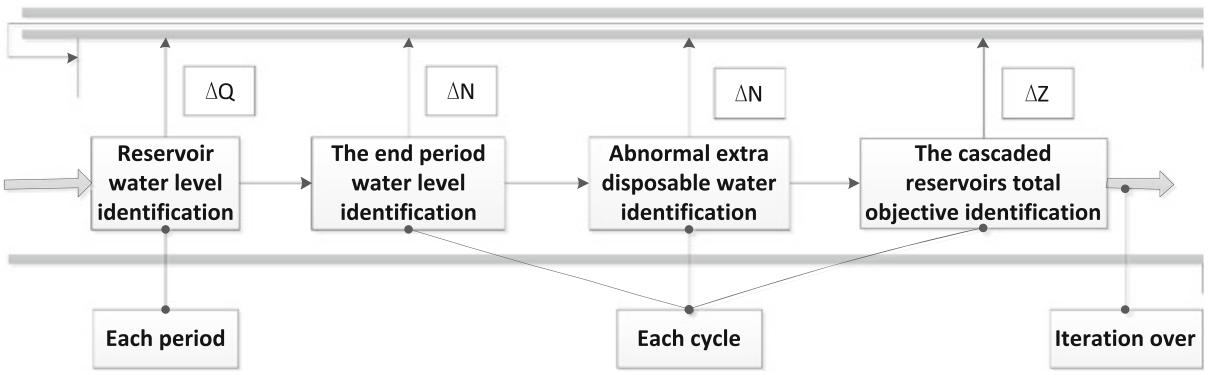

Fig. 3 Schematic of the feedback structure

$4920 \mathrm{~m}^{3} / \mathrm{s}$ (2010). At present, the $1500 \mathrm{~km}$ long middle and lower sections of the mainstream from Shigu to Yibin is planned and developed for the Cascade hydropower exploitation (CHE) base at Jinsha River. The total installed capacity of the base is 51395 MW and its annual generating capacity is 248.58TWh (2008). It is China's largest CHE base and the main supply for the "West-east Electricity Transfer Project". The $700 \mathrm{~km}$-long section of mainstream from Shigu to Panzhihua is the middle reaches of the Jinsha River, where 8 cascades (Fig. 4) are planned with the installed capacity of 20580 MW. And they are charged by four investments.

The six power plants of the lower reaches are to be completed at first because Longpan Hydropower Station and Liangjiaren are now in the demonstration phase. So how to manage the operation mode of the six stage cascade hydropower stations previously formed is a serious problem The regulation performances of the six power stations are all poor, for their regulating periods are only daily or weekly. And their investment subjects are not unified. So it is very necessary to compare the benefit of the separated to the combined operation with different combinations and different production phases, which is the important

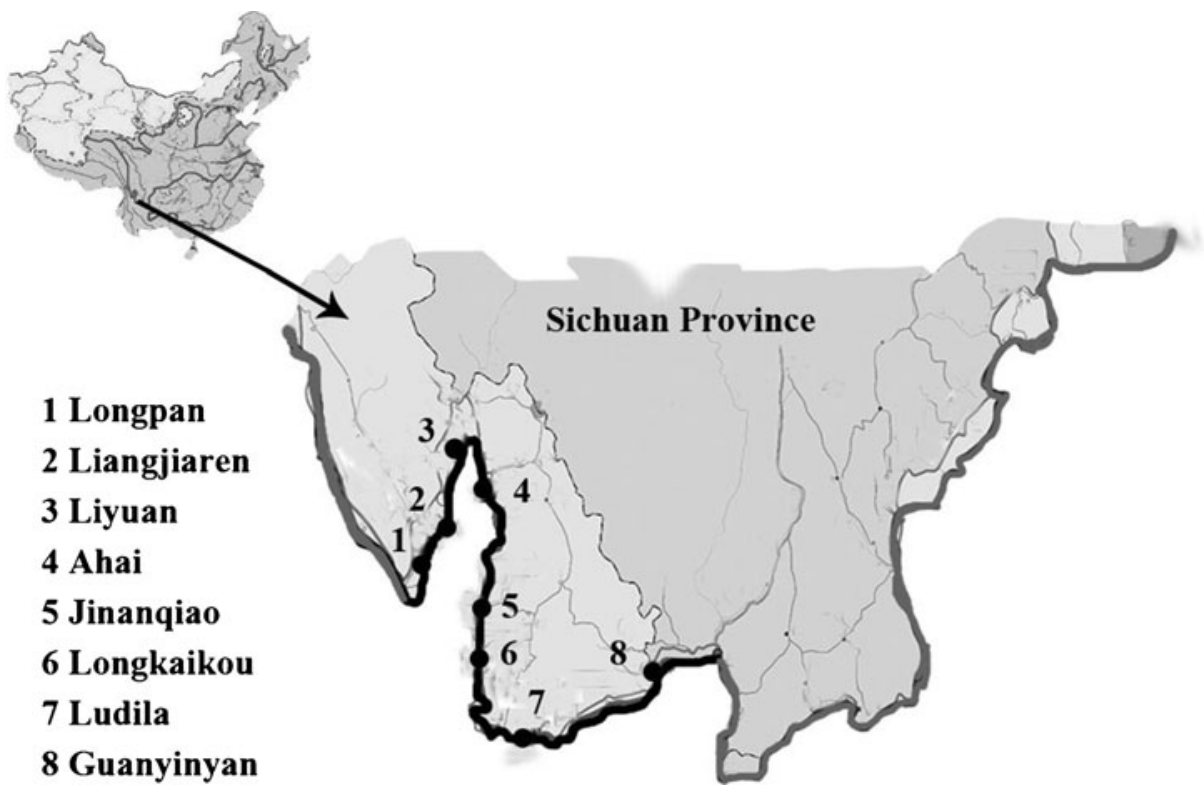

Fig. 4 Overview map of the Jinsha river planning 
demonstration for realizing the water resources optimal allocation. This paper at first generalizes the real reservoir system and each reservoir is selected as the compute nodes. Then through the analysis of the runoff data, three representative years: wet year, normal year, dry year are chosen, and the system simulates and schedules with the typical daily runoff and the corresponding daily load curves of each month of the chosen years. There are three typical days selected of each month, one is the day that the daily average flow is most close to the monthly average, and the other 2 days are the minimum and maximum daily average flow, respectively.

The typical daily load curves predicted of Yunnan in 2015 (wet season and dry season) are chosen to use in this article. At the same time, the distances between the cascade hydropower stations are small because of the connected type connection. And the upstream power station discharge can spread rapidly to the downstream station. So the coefficients mentioned above are confirmed as the following $\tau=0, \gamma=0$, as a result the flatting coefficient $\mathrm{e}^{\gamma}=1$.

Before the leading power (Longpan Hydropower Station) being put into operation, the six power stations have been divided into five scheduling combinations because of their different accomplished and operating time. The first is the separated and combined operation of Jinanqiao, Longkaikou (combination one); the second is the separated and combined operation of Jinanqiao, Longkaikou, Ludila (combination two); the third is the separated and combined operation of Ahai, Jinanqiao, Longkaikou, Ludila (combination three); the forth is the separated and combined operation of Liyuan, Ahai, Jinanqiao, Longkaikou, Ludila (combination four); the fifth is the separated and combined operation of Liyuan, Ahai, Jinanqiao, Longkaikou, Ludila, Guanyinyan (combination five). At last it is to compare the benefit of the separated operation with the combined for the each combination in different phases.

\section{Results and Discussion}

With the self-optimization and simulation model and the special solving technique, the benefits of the separated operation were compared to the combined operation for each combination in different production periods. This paper selects combination five to analyze, and the results are as follows. Noting: the daily power generation in the table actually is an average data of each month.

Viewing on the data of the three typical years in Tables 1,2 and 3, the monthly total generating capacity of each reservoir is improved to a certain extent when the results of the combined scheduling are compared to the separated scheduling's. The relatively large growth is from February to April, because the 5 months belong to water supply periods with less incoming water. The scheduling compensation and coordination of the electric quantity and water volume among the cascade reservoirs are reflected better, especially for the combined operation. The generation power from July to October of wet year has no difference between the separated operation and the combined operation, for the incoming water in flood season of wet year is so large that the installed capacity is almost generated by the reservoirs. Besides, the monthly power generation growth of normal year and dry year is larger than the wet year. The main reason is that the reservoir inflow of the two typical years is relatively smaller than the wet year, so the effect of the combined dispatching is more obvious. The cascade total generating capacity analysis chart is shown in Table 4 and Figs. 5, 6 and 7:

According to the tables and figures, the monthly changing tendency of cascade total generating capacity is basically consistent with the single reservoir, and each monthly generation of the three typical years has a certain growth. Actually, there is a direct 


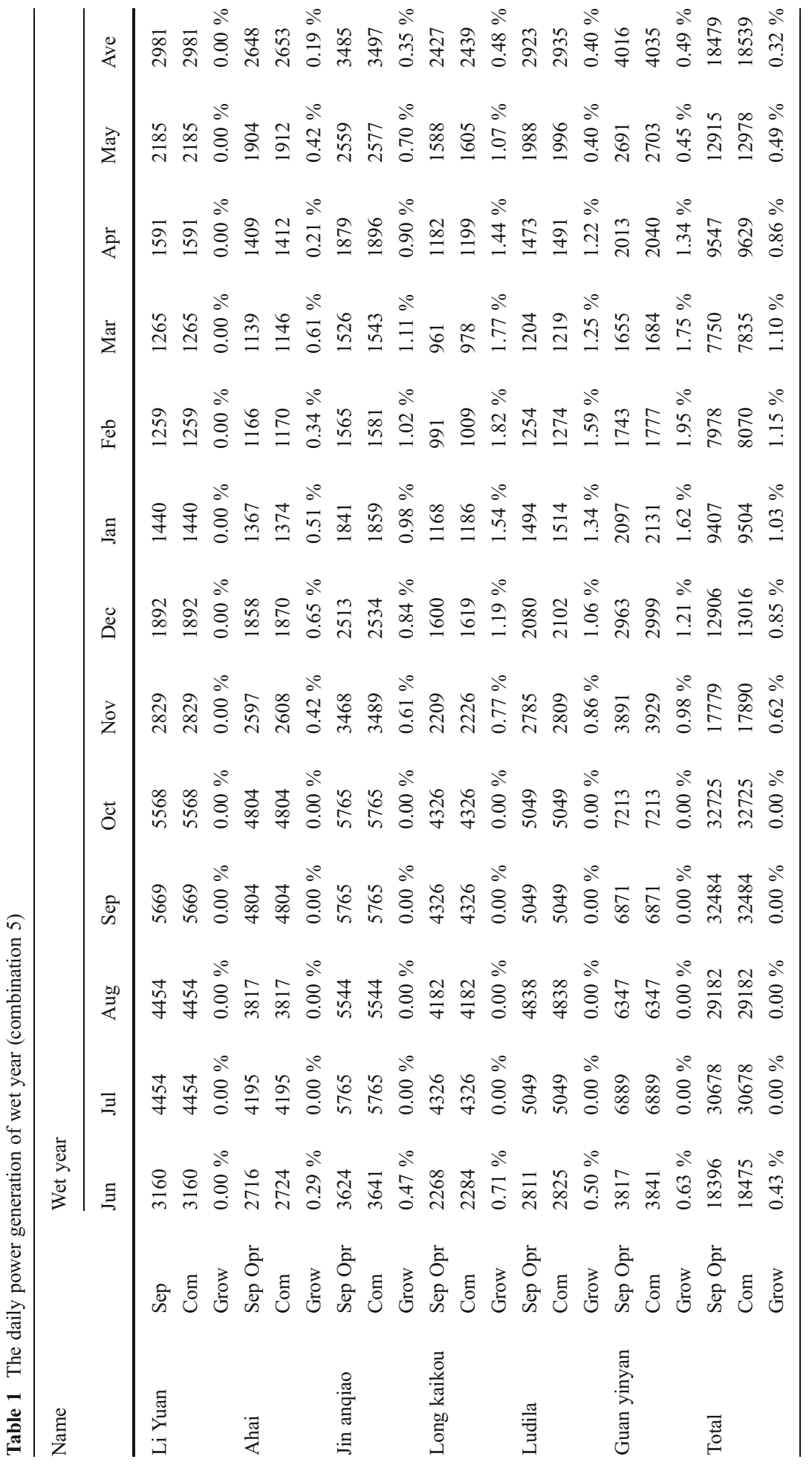




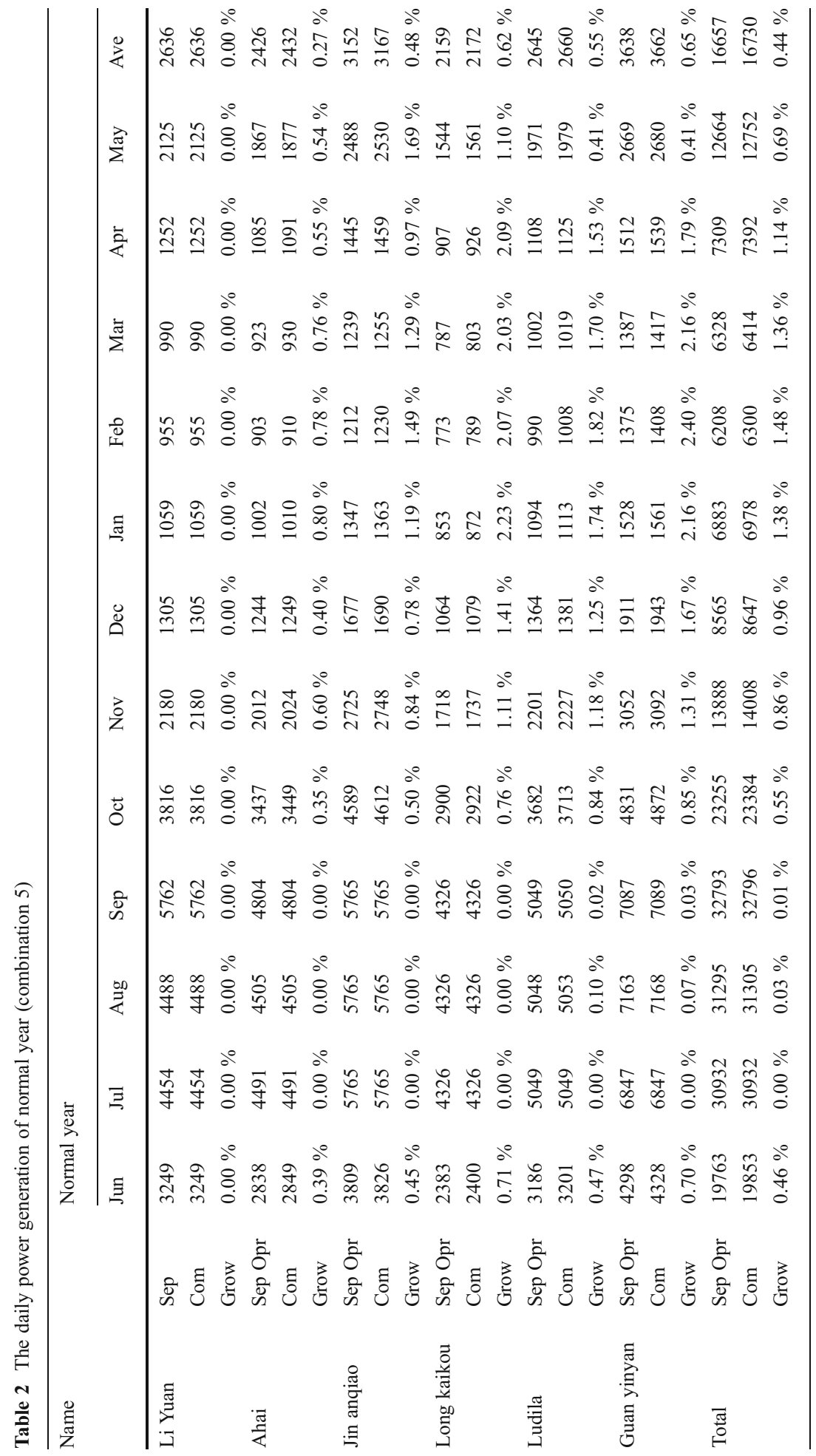




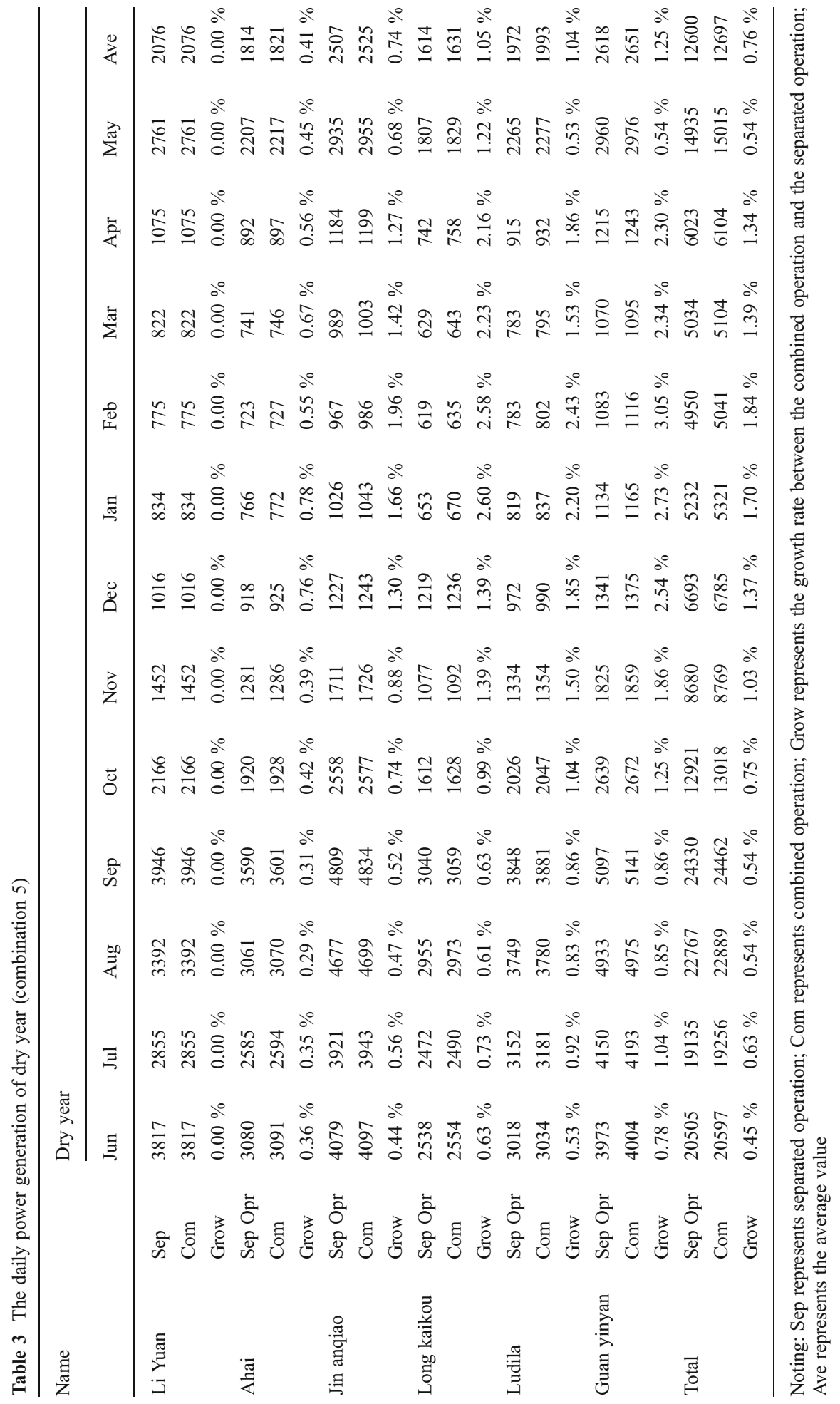


Table 4 Total generating capacity of the cascade system (combination 5)

\begin{tabular}{|c|c|c|c|c|c|c|c|c|c|}
\hline \multirow[t]{2}{*}{ Name } & \multicolumn{3}{|c|}{ Wet year } & \multicolumn{3}{|c|}{ Normal year } & \multicolumn{3}{|c|}{ Dry year } \\
\hline & Sep & Com & Growth & Sep & Com & Growth & Sep & Com & Growth \\
\hline Jun & 18396 & 18475 & $0.43 \%$ & 19763 & 19853 & $0.46 \%$ & 20505 & 20597 & $0.45 \%$ \\
\hline Jul & 30678 & 30678 & $0.00 \%$ & 30932 & 30932 & $0.00 \%$ & 19135 & 19256 & $0.63 \%$ \\
\hline Aug & 29182 & 29182 & $0.00 \%$ & 31295 & 31305 & $0.03 \%$ & 22767 & 22889 & $0.54 \%$ \\
\hline Sep & 32484 & 32484 & $0.00 \%$ & 32793 & 32796 & $0.01 \%$ & 24330 & 24462 & $0.54 \%$ \\
\hline Oct & 32725 & 32725 & $0.00 \%$ & 23255 & 23384 & $0.55 \%$ & 12921 & 13018 & $0.75 \%$ \\
\hline Nov & 17779 & 17890 & $0.62 \%$ & 13888 & 14008 & $0.86 \%$ & 8680 & 8769 & $1.03 \%$ \\
\hline Dec & 12906 & 13016 & $0.85 \%$ & 8565 & 8647 & $0.96 \%$ & 6693 & 6785 & $1.37 \%$ \\
\hline Jan & 9407 & 9504 & $1.03 \%$ & 6883 & 6978 & $1.38 \%$ & 5232 & 5321 & $1.70 \%$ \\
\hline Feb & 7978 & 8070 & $1.15 \%$ & 6208 & 6300 & $1.48 \%$ & 4950 & 5041 & $1.84 \%$ \\
\hline Mar & 7750 & 7835 & $1.10 \%$ & 6328 & 6414 & $1.36 \%$ & 5034 & 5104 & $1.39 \%$ \\
\hline Apr & 9547 & 9629 & $0.86 \%$ & 7309 & 7392 & $1.14 \%$ & 6023 & 6104 & $1.34 \%$ \\
\hline May & 12915 & 12978 & $0.49 \%$ & 12664 & 12752 & $0.69 \%$ & 14935 & 15015 & $0.54 \%$ \\
\hline Ave & 18479 & 18539 & $0.32 \%$ & 16657 & 16730 & $0.44 \%$ & 12600 & 12697 & $0.76 \%$ \\
\hline
\end{tabular}

relationship between the cascade total generating capacity and the incoming water. In February, the inflow is the least of the three typical kind years, so the growth of the cascaded total generating capacity is the largest with the combined operation of cascade reservoirs.

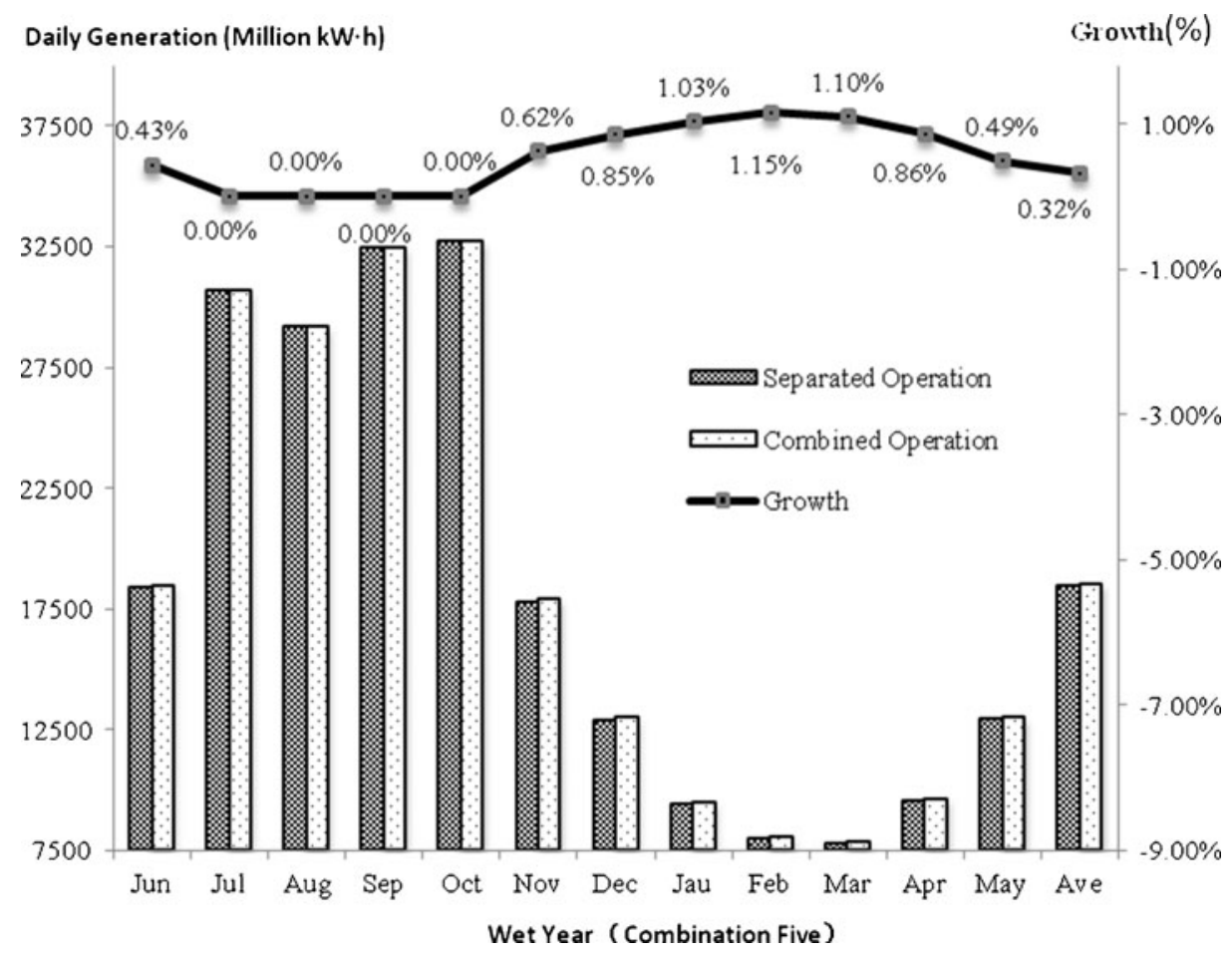

Fig. 5 Total generating capacity comparing the separated with combined operation (wet year) 


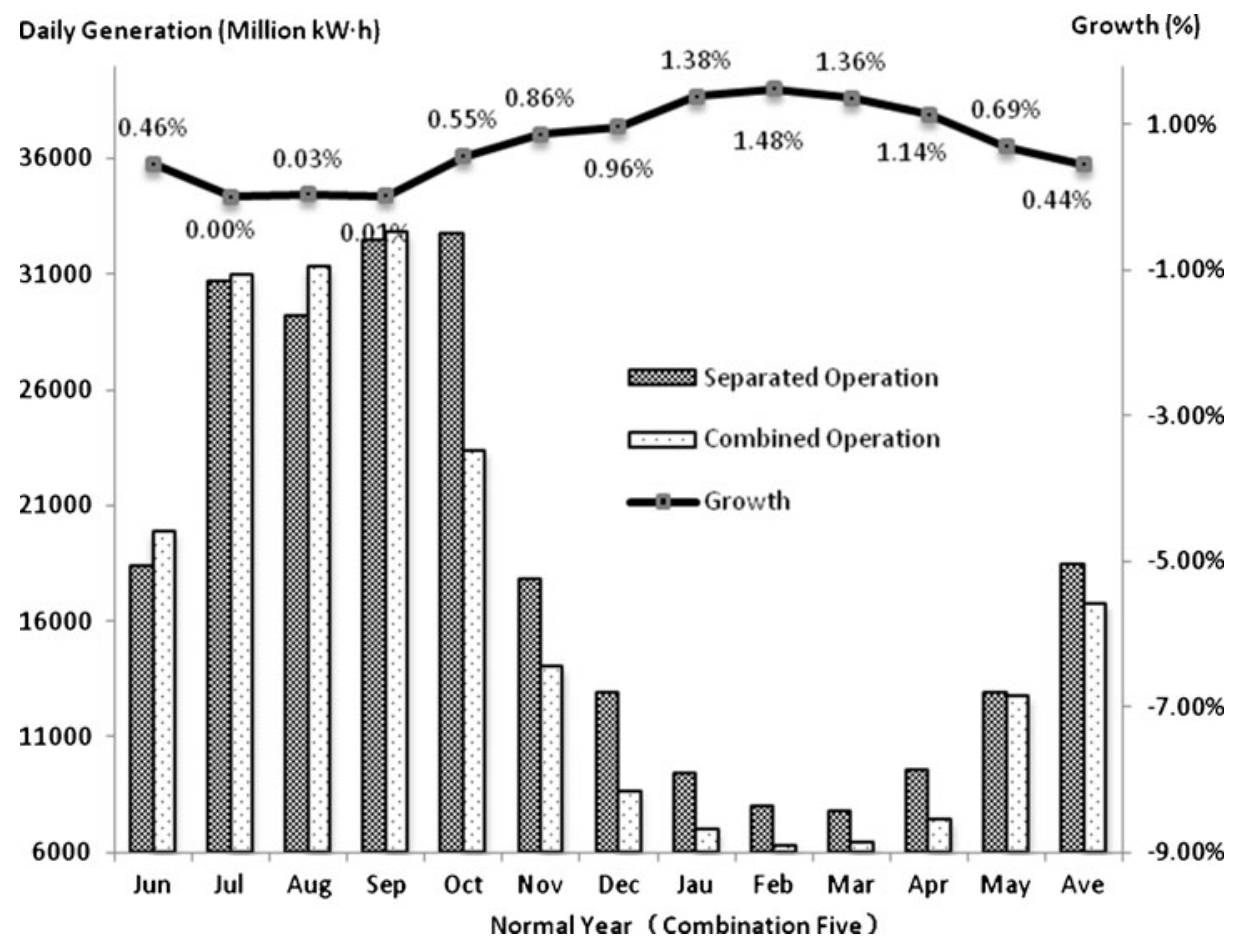

Fig. 6 Total generating capacity comparing the separated with combined operation (normal year)

From the whole view, the incoming water of the dry year and normal year is certainly less than the wet year, therefore their increasing rate of the total generating capacity is much larger compared to the wet year, and the largest growth obviously happens in the dry year. But to the total quantities of the cascaded generating capacity, there is no doubt that the number of the wet year is the largest, because relatively adequate incoming water will inevitably generate more power. The analysis of the total power generation capacity data for each combination and each typical year is listed in Table 5.

From the perspective of the overall analysis of the data, for the five combinations of different startup time, when the results of the combined operation are compared to the separate operation's, whether is in wet year, or normal year, or dry year, all the total power generation capacity has increased in some degree a. And the average percentage growth of the daily power generation is between $0.03 \%$ and $0.76 \%$. The main reason can be described as follows: when it is in the separated operation, the discharging process of the upstream power station cannot be predicted accurately by the lower station, so appropriate storage is reserved in order to avoid the unnecessary abandoned water; then a problem comes into being that the total quantity of the power generation has been reduced because of the relative low running water head; but when it is of the combined operation the cascaded system following the "daily load scheduling model", the discharge process of the upstream station is able to be used by the downstream power station directly since it is consistent with the daily load curve as far as possible; as a result the total power production has been increased for the station can keep operating with high head in most periods.

From the point of view of the five combinations in different production period, it can be deduced from comparing the combined operation to the separated operation, no matter in 


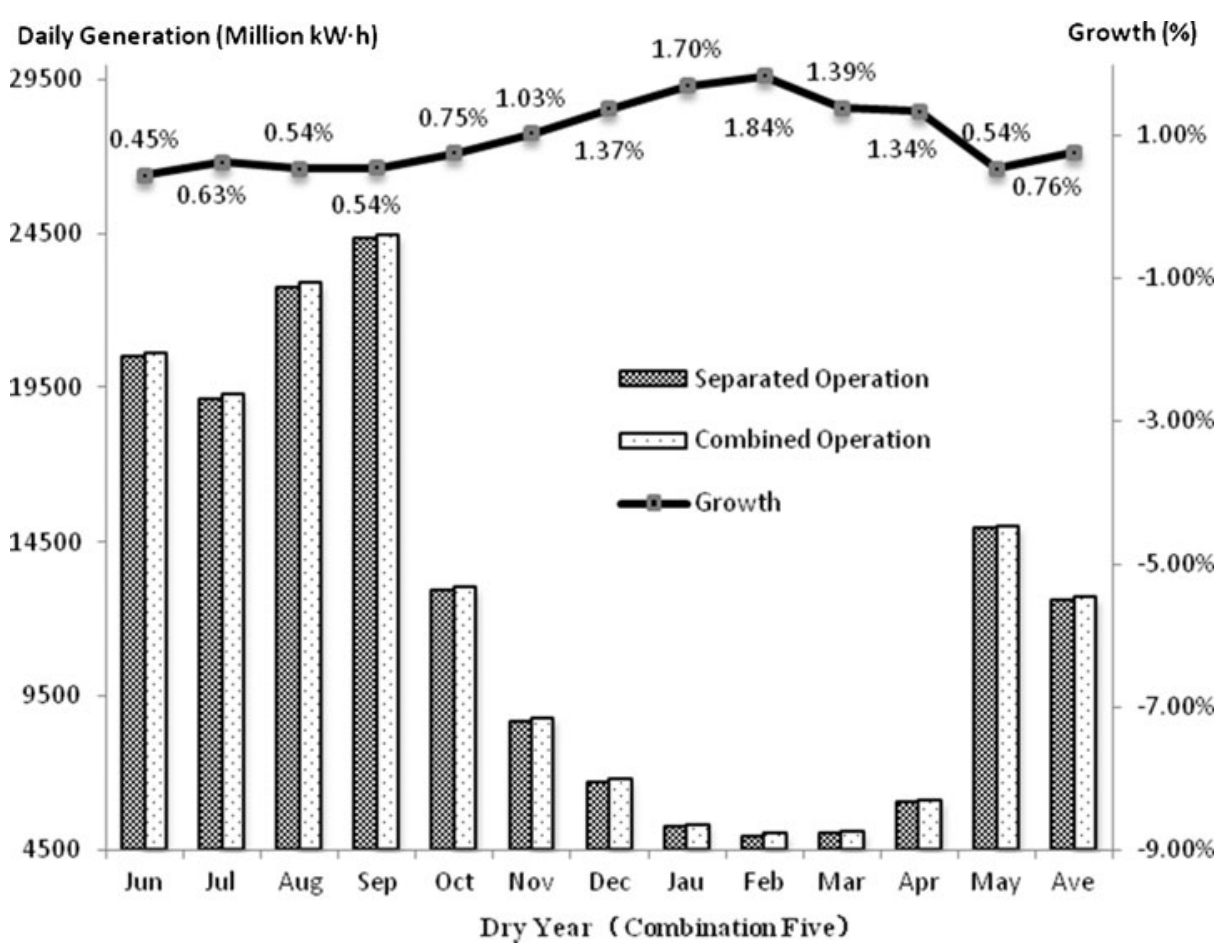

Fig. 7 Total generating capacity comparing the separated with combined operation (dry year)

which typical year, the growth degree of the output is increased with the added number of the cascade hydropower group. Because more reservoirs in the cascaded system mean more room to be adjusted, so the lower station of the combined operation runs with relative high water head. Viewing on the data of the three typical years, no matter which combination it is, the generation growth of the combined operation in dry year is all higher than in wet and normal year. As there are more scheduling periods with the expected output in wet and

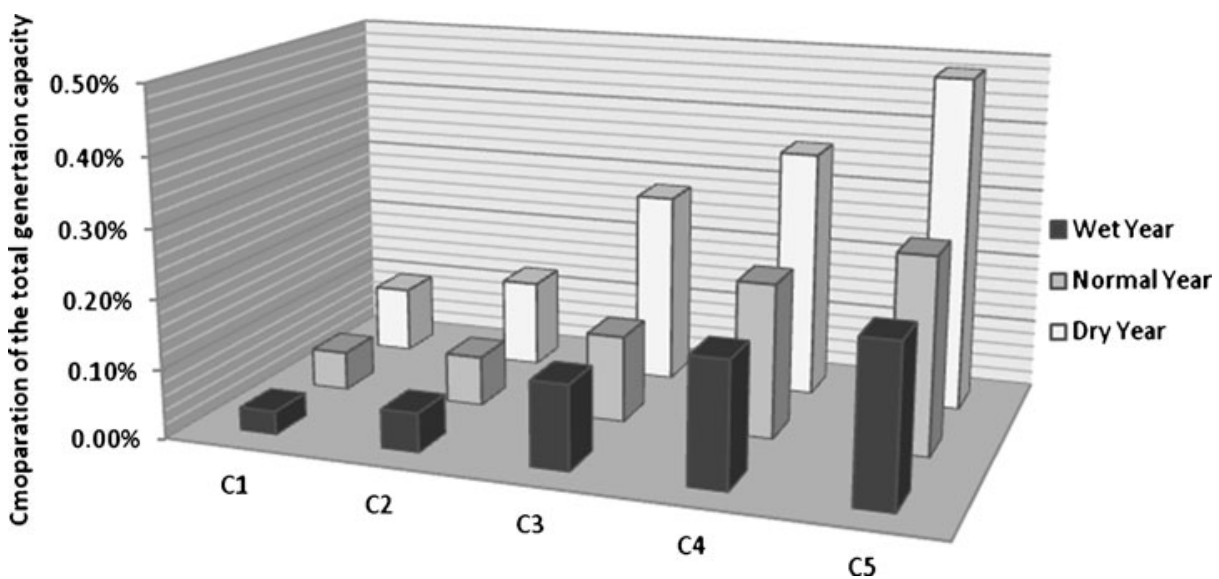

Fig. 8 The growth of total power generation capacity for each combination and each typical year 
Table 5 Total power generation capacity for each combination and each typical year

\begin{tabular}{|c|c|c|c|c|c|c|c|c|c|c|}
\hline \multicolumn{2}{|c|}{ Name } & \multicolumn{3}{|c|}{ Wet year } & \multicolumn{3}{|c|}{ Normal year } & \multicolumn{3}{|c|}{ Dry year } \\
\hline & & Sep & Com & Growth & Sep & Com & Growth & Sep & Com & Growth \\
\hline \multirow[t]{3}{*}{$\mathrm{C} 1$} & Jinanqiao & 3483 & 3483 & $0.00 \%$ & 3149 & 3149 & $0.00 \%$ & 2511 & 2511 & $0.00 \%$ \\
\hline & Longkaikou & 2430 & 2432 & $0.08 \%$ & 2155 & 2158 & $0.14 \%$ & 1609 & 1613 & $0.25 \%$ \\
\hline & Cascaded & 5913 & 5915 & $0.03 \%$ & 5304 & 5307 & $0.06 \%$ & 4120 & 4124 & $0.10 \%$ \\
\hline \multirow[t]{4}{*}{$\mathrm{C} 2$} & Jinanqiao & 3483 & 3483 & $0.00 \%$ & 3483 & 3483 & $0.00 \%$ & 3483 & 3483 & $0.00 \%$ \\
\hline & Longkaikou & 2430 & 2432 & $0.08 \%$ & 2155 & 2158 & $0.14 \%$ & 1609 & 1613 & $0.25 \%$ \\
\hline & Ludila & 2917 & 2920 & $0.10 \%$ & 2638 & 2641 & $0.11 \%$ & 1965 & 1970 & $0.25 \%$ \\
\hline & Cascaded & 8830 & 8835 & $0.06 \%$ & 8276 & 8282 & $0.07 \%$ & 7057 & 7066 & $0.13 \%$ \\
\hline \multirow[t]{5}{*}{$\mathrm{C} 3$} & Ahai & 2645 & 2645 & $0.00 \%$ & 2423 & 2423 & $0.00 \%$ & 1810 & 1810 & $0.00 \%$ \\
\hline & Jinanqiao & 3479 & 3485 & $0.17 \%$ & 3145 & 3149 & $0.13 \%$ & 2499 & 2506 & $0.28 \%$ \\
\hline & Longkaikou & 2423 & 2427 & $0.17 \%$ & 2151 & 2156 & $0.23 \%$ & 1606 & 1613 & $0.44 \%$ \\
\hline & Ludila & 2917 & 2921 & $0.14 \%$ & 2636 & 2640 & $0.15 \%$ & 1963 & 1971 & $0.41 \%$ \\
\hline & Cascaded & 11464 & 11478 & $0.12 \%$ & 10355 & 10368 & $0.13 \%$ & 7878 & 7900 & $0.28 \%$ \\
\hline \multirow[t]{6}{*}{$\mathrm{C} 4$} & Liyuan & 2979 & 2979 & $0.00 \%$ & 2633 & 2633 & $0.00 \%$ & 2074 & 2074 & $0.00 \%$ \\
\hline & Ahai & 2647 & 2650 & $0.11 \%$ & 2424 & 2428 & $0.17 \%$ & 1810 & 1813 & $0.17 \%$ \\
\hline & Jinanqiao & 3480 & 3488 & $0.23 \%$ & 3150 & 3158 & $0.25 \%$ & 2506 & 2517 & $0.44 \%$ \\
\hline & Longkaikou & 2429 & 2436 & $0.29 \%$ & 2161 & 2169 & $0.37 \%$ & 1616 & 1626 & $0.62 \%$ \\
\hline & Ludila & 2924 & 2932 & $0.27 \%$ & 2648 & 2657 & $0.34 \%$ & 1976 & 1988 & $0.61 \%$ \\
\hline & Cascaded & 14459 & 14485 & $0.18 \%$ & 13016 & 13045 & $0.22 \%$ & 9982 & 10018 & $0.36 \%$ \\
\hline \multirow[t]{7}{*}{$\mathrm{C} 5$} & Liyuan & 2981 & 2981 & $0.00 \%$ & 2636 & 2636 & $0.00 \%$ & 2076 & 2076 & $0.00 \%$ \\
\hline & Ahai & 2648 & 2653 & $0.19 \%$ & 2426 & 2432 & $0.27 \%$ & 1814 & 1821 & $0.41 \%$ \\
\hline & Jinanqiao & 3485 & 3497 & $0.35 \%$ & 3152 & 3167 & $0.48 \%$ & 2507 & 2525 & $0.74 \%$ \\
\hline & Longkaikou & 2427 & 2439 & $0.48 \%$ & 2159 & 2172 & $0.62 \%$ & 1614 & 1631 & $1.05 \%$ \\
\hline & Ludila & 2923 & 2935 & $0.40 \%$ & 2645 & 2660 & $0.55 \%$ & 1972 & 1993 & $1.04 \%$ \\
\hline & Guanyinyan & 4016 & 4035 & $0.49 \%$ & 3638 & 3662 & $0.65 \%$ & 2618 & 2651 & $1.25 \%$ \\
\hline & Cascaded & 18479 & 18539 & $0.32 \%$ & 16657 & 16730 & $0.44 \%$ & 12600 & 12697 & $0.76 \%$ \\
\hline
\end{tabular}

Noting: $\mathrm{C}$ is Combination

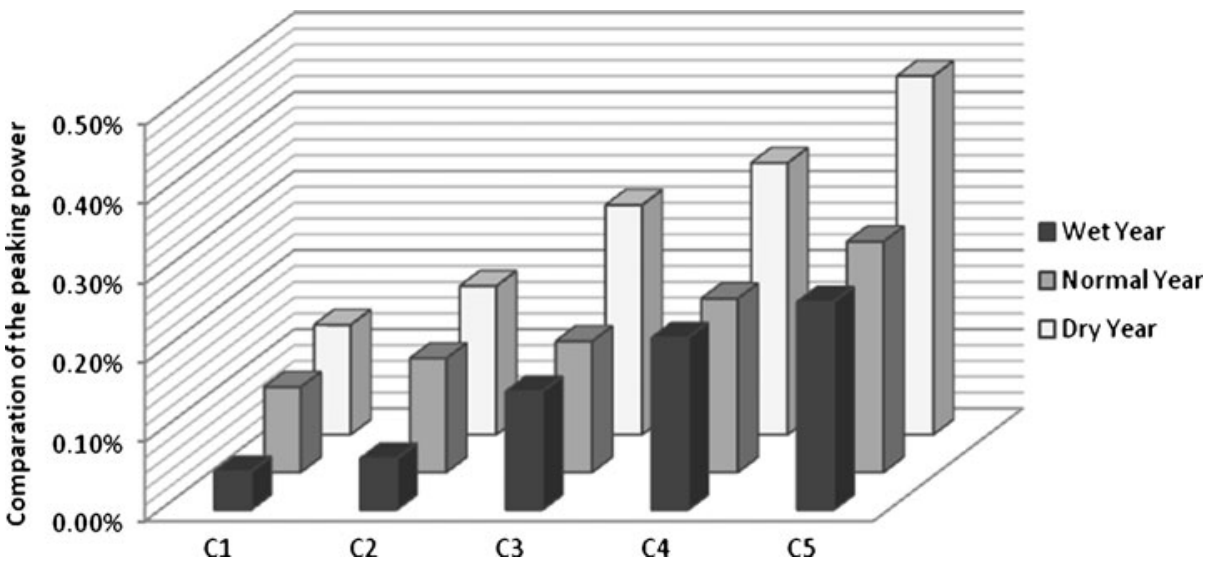

Fig. 9 The growth of total peaking power capacity for each combination and each typical year 
normal year because of the relative sufficient water inflow. Then in result the advantages of the combined operation are not very obvious. But in dry year, the advantages of the combined operation in expanding the output regulation range are expressed better because of the less water inflow. It can be seen clearly from the following three dimensional graphs (Fig. 9).

Under the mode of daily load scheduling, another target of the same self-optimization simulation model is to ensure the maximum peaking capacity as far as possible, and the results of peak regulation are shown in Table 6.

The overall analysis of the table data shows that, for the five combinations in the different startup periods, the total peaking power capacity of the combined operation has increased in a certain degree comparing to the separated operation, and the average growth percentage of the daily peaking power capacity is between $0.05 \%$ and $0.45 \%$. And this growth is proportional to increase along with the increasing number of the power stations in the combination. In view of the three typical years, the peaking power growth of each combination in dry year is higher than in wet year and normal year. The analyzed results are shown in the following three dimensional graphs (Fig. 9).

Table 6 Total peaking power capacity for each combination and each typical year

\begin{tabular}{|c|c|c|c|c|c|c|c|c|c|c|}
\hline \multirow[t]{2}{*}{ Name } & \multirow[t]{2}{*}{ Reservior } & \multicolumn{3}{|c|}{ Wet year } & \multicolumn{3}{|c|}{ Normal year } & \multicolumn{3}{|c|}{ Dry year } \\
\hline & & Sep & Com & Growth & Sep & Com & Growth & Sep & Com & Growth \\
\hline \multirow[t]{3}{*}{$\mathrm{C} 1$} & Jinanqiao & 1219 & 1219 & $0.00 \%$ & 1102 & 1102 & $0.00 \%$ & 879 & 879 & $0.00 \%$ \\
\hline & Longkaikou & 851 & 852 & $0.12 \%$ & 754 & 756 & $0.27 \%$ & 563 & 565 & $0.36 \%$ \\
\hline & Cascaded & 2070 & 2071 & $0.05 \%$ & 1856 & 1858 & $0.11 \%$ & 1442 & 1444 & $0.14 \%$ \\
\hline \multirow[t]{4}{*}{$\mathrm{C} 2$} & Jinanqiao & 1219 & 1219 & $0.00 \%$ & 1102 & 1102 & $0.00 \%$ & 879 & 879 & $0.00 \%$ \\
\hline & Longkaikou & 851 & 852 & $0.12 \%$ & 754 & 756 & $0.27 \%$ & 563 & 565 & $0.36 \%$ \\
\hline & Ludila & 1021 & 1022 & $0.10 \%$ & 923 & 925 & $0.22 \%$ & 688 & 690 & $0.29 \%$ \\
\hline & Cascaded & 3091 & 3093 & $0.06 \%$ & 2779 & 2783 & $0.14 \%$ & 2130 & 2134 & $0.19 \%$ \\
\hline \multirow[t]{5}{*}{ C3 } & Ahai & 926 & 926 & $0.00 \%$ & 848 & 848 & $0.00 \%$ & 634 & 634 & $0.00 \%$ \\
\hline & Jinanqiao & 1218 & 1220 & $0.16 \%$ & 1101 & 1103 & $0.18 \%$ & 875 & 878 & $0.34 \%$ \\
\hline & Longkaikou & 848 & 850 & $0.24 \%$ & 753 & 755 & $0.27 \%$ & 562 & 564 & $0.36 \%$ \\
\hline & Ludila & 1021 & 1023 & $0.20 \%$ & 923 & 925 & $0.22 \%$ & 687 & 690 & $0.44 \%$ \\
\hline & Cascaded & 4013 & 4019 & $0.15 \%$ & 3625 & 3631 & $0.17 \%$ & 2758 & 2766 & $0.29 \%$ \\
\hline \multirow[t]{6}{*}{$\mathrm{C} 4$} & Liyuan & 1043 & 1043 & $0.00 \%$ & 922 & 922 & $0.00 \%$ & 726 & 726 & $0.00 \%$ \\
\hline & Ahai & 926 & 928 & $0.22 \%$ & 848 & 850 & $0.24 \%$ & 634 & 635 & $0.16 \%$ \\
\hline & Jinanqiao & 1218 & 1221 & $0.25 \%$ & 1103 & 1105 & $0.18 \%$ & 877 & 881 & $0.46 \%$ \\
\hline & Longkaikou & 850 & 853 & $0.35 \%$ & 756 & 759 & $0.40 \%$ & 566 & 569 & $0.53 \%$ \\
\hline & Ludila & 1023 & 1026 & $0.29 \%$ & 927 & 930 & $0.32 \%$ & 692 & 696 & $0.58 \%$ \\
\hline & Cascaded & 5060 & 5071 & $0.22 \%$ & 4556 & 4566 & $0.22 \%$ & 3495 & 3507 & $0.34 \%$ \\
\hline \multirow[t]{7}{*}{$\mathrm{C} 5$} & Liyuan & 1043 & 1043 & $0.00 \%$ & 922 & 922 & $0.00 \%$ & 726 & 726 & $0.00 \%$ \\
\hline & Ahai & 926 & 928 & $0.22 \%$ & 848 & 850 & $0.24 \%$ & 634 & 635 & $0.16 \%$ \\
\hline & Jinanqiao & 1218 & 1221 & $0.25 \%$ & 1103 & 1105 & $0.18 \%$ & 877 & 881 & $0.46 \%$ \\
\hline & Longkaikou & 850 & 853 & $0.35 \%$ & 756 & 759 & $0.40 \%$ & 566 & 569 & $0.53 \%$ \\
\hline & Ludila & 1023 & 1026 & $0.29 \%$ & 927 & 930 & $0.32 \%$ & 692 & 696 & $0.58 \%$ \\
\hline & Guanyinyan & 1407 & 1413 & $0.43 \%$ & 1275 & 1282 & $0.55 \%$ & 919 & 927 & $0.87 \%$ \\
\hline & Cascaded & 6467 & 6484 & $0.26 \%$ & 5831 & 5848 & $0.29 \%$ & 4414 & 4434 & $0.45 \%$ \\
\hline
\end{tabular}


The middle reaches of hydropower station operation plan and formulates the scheduling rules Power operation plan and scheduling rules of cascade hydropower stations in Jinsha River middle reaches research.

\section{Conclusion}

This study applied the characteristics of self-optimization simulation technology, such as the clear physical meaning, more perfect simulation, no dimension limitation, artificial adjustment with the accumulated experience and so on. Simultaneously giving enough thought to the requirements of the daily load curve, a self-optimization simulation model was developed for the short-term cascaded hydroelectric system scheduling. This model took both of the supply and demand sides' requirements into account. The first task was to keep power grids operate safely and stably, and then pursued the maximum total power generation capacity and the maximum peaking capacity. The methodology was implemented for the cascaded hydroelectric system in the middle reaches of Chinese Jinsha River under the conditions of different production periods and combinations. From the table and figure data above, as to the station of each combination with different startup time, whether for the total generating capacity or the peaking power, it had been demonstrated that there was probable improvement of comprehensive benefits comparing the combined operation to the separated operation. Because the combined operation could embody the advantages of the electricity and hydraulic contacts well. The average growth rate of combination operation is between $0.20 \%$ and $48 \%$, and the additional generation capacity of each year is between 132 million kilowatt-hours and 279 million kilowatt-hours. Viewing on the contribution to the social benefit, the above data was about relative 5.8 13.0 ten thousand tons coal saved, or 13.4 29.7 ten thousand tons carbon dioxide emissions reduced. So the demonstrated results were of great help for the different development bodies to implement the combined operation, and had important significance in implementing the national policy of energy-saving and emission reduction.

Although this study is the first attempt for solving the multi-objective short cascaded hydropower scheduling problem with the self-optimization simulation technology, the special solving method makes the operation plans satisfactory, and it is more probable to put this scheduling scheme into practice. When the leading power plant has been demonstrated successfully and begins to operate in practice, it will generate a new significant subject of the combined operation with the eight cascaded hydropower station group. So the further study will be aimed at formulating the scheduling scheme of the eight cascaded hydropower station, and the plan inevitably plays an important part in transporting and utilizing the hydroelectricity in the middle reaches of Jinsha River.

Open Access This article is distributed under the terms of the Creative Commons Attribution License which permits any use, distribution, and reproduction in any medium, provided the original author(s) and the source are credited.

\section{References}

Afzali R, Mousavi SJ, Ghaheri A (2008) Reliability based simulation-optimization model for multi reservoir hydropower system operations: Khersan experience. J Water Resour Plann Manag 134(1):24-33

Catalao J, Pousinho H (2010) Scheduling of head-dependent cascaded hydro systems: mixed-integer quadratic programming approach. Energy Convers Manage 51(3):524-530 
Khan NM, Babel MS (2012) Reservoir optimization-simulation with a sediment evacuation model to minimize irrigation deficits. Water Resour Manag 26:3173-3193

Lei SL (1989) Self-optimization simulation and its application in the project of South to North water transfer. J Hydraul Eng 5:1-13

Li HA (2000) Research on the self-optimization simulation model for reservoirs real time operation for the main stream of the upper Yellow River. J Hydroelect Eng 3:55-61

OECD/IEA (2007) Key world energy statistics

Oliveiraa A, Soaresb S (2005) Short term hydroelectric scheduling combining network flow and interior point approaches. Int J Elect Power 27(2):91-99

Ostadrahimi L, Miguel A (2012) Multi-reservoir operation rules: multi-swarm PSO-based optimization approach. Water Resour Manag 26:407-427

Pekala LM, Tan RR, Foo DCY, Jezowski JM (2010) Optimal energy planning models with carbon footprint constraints. Applied Energy 86:1903-1910

Yu S (2012) Short-term operation benefit analysis of cascade reservoirs based on power load curve. Power Syst Protect Control 39(14):64-74

Yuan XH et al (2010) Optimal self-scheduling of hydro producer in the electricity market. Energy Convers Manage 51(12):2523-2530

Zhang GF (2004) Study on short-term optimal operation and automatic generation control of cascade hydro system. Ph.D thesis of Huazhong university of science and technology: Wuhan China. 